\title{
(CAAC)Copper Catalysis Enables Regioselective Three- Component Carboboration of Terminal Alkynes
}

\author{
Yang Gao ${ }^{[a]}$ Nana Kim, ${ }^{[a]}$ Sima Yazdani, ${ }^{[b]}\left[{ }^{[c]}\right.$ Mingyu Liu, ${ }^{[a]}$ Aaron Kendrick IV, ${ }^{[a]}$ Douglas B. Grotjahn, ${ }^{[c]}$ \\ Guy Bertrand ${ }^{*}{ }^{[b]}$ Rodolphe Jazzar ${ }^{*},{ }^{[b]}$ Keary M. Engle ${ }^{*[a]}$
}

[a] Dr. Y. Gao, Dr. N. Kim, Dr. M. Liu, A. Kendrick IV, Prof. K. M. Engle

Department of Chemistry

The Scripps Research Institute

10550 N Torrey Pines Road, La Jolla, CA 92037-1000 (USA)

E-mail: keary@scripps.edu

[b] Dr. S. Yazdani, Prof. G. Bertrand, Dr. R. Jazzar

UCSD-CNRS Joint Research Laboratory (IRL 3555),

Department of Chemistry and Biochemistry

University of California, San Diego

La Jolla, CA 92093-0358 (USA)

[c] Dr. S. Yazdani, Prof. D. B. Grotjahn

Department of Chemistry and Biochemistry

San Diego State University

5500 Campanile Drive, San Diego, CA 92182-1030 (USA)

Supporting information for this article is given via a link at the end of the document.

\begin{abstract}
Cyclic(alkyl)(amino)carbene (CAAC) ligands are found to perturb regioselectivity of the copper-catalyzed carboboration of terminal alkynes, favoring the less commonly observed internal alkenylboron regiosomer through an $\alpha$-selective borylcupration step. A variety of carbon electrophiles participate in the reaction, including allyl alcohols derivatives and alkyl halides. The method provides a straightforward and selective route to versatile tri-substituted alkenylboron compounds that are otherwise challenging to access.
\end{abstract}

Organoboron compounds play a unique role in the chemical sciences. Carbon-boron bonds can readily be converted into a diverse array of carbon-carbon and carbon-heteroatom linkages via an ever-expanding battery of methods, ${ }^{[1-4]}$ and organoboron molecules themselves possess myriad of functions in the context of biology ${ }^{[5-6]}$ and materials science. ${ }^{[7-9]}$ Inventing new methods to assemble organoboron compounds from simple chemical inputs streamlines access to important family of molecules. Multicomponent catalytic couplings, in which three or more building blocks are united in a single step, hold tremendous promise in enabling direct synthesis of densely functionalized organoboron compounds. In this context, copper-catalyzed borylative 1,2difunctionalization of alkynes is an established means of preparing tri- and tetrasubstitued alkenylboron targets via a mechanism involving migratory insertion of an alkyne into a $\mathrm{L}_{n} \cdot \mathrm{Cu}$-boryl intermediate followed by coupling of the resulting $\mathrm{L}_{n} \cdot \mathrm{Cu}^{\prime}$ (alkenyl) species with an electrophile. ${ }^{[10-13]}$ Controlling the regioselectivity of these processes in a way that grants access to either regioisomer in a predictable manner remains challenging. With terminal alkynes, the vast majority of catalytic systems deliver the boryl group to the terminal $(\beta)$ position, restricting access to the opposite alkenylboron regioisomers. Here, we demonstrate that appropriately tuned cyclic(alkyl)(amino)carbene (CAAC)-ligated copper catalysts enables regioselective carboboration to give internal $(\alpha)$ alkenylboron compounds with a broad collection of carbon electrophiles.

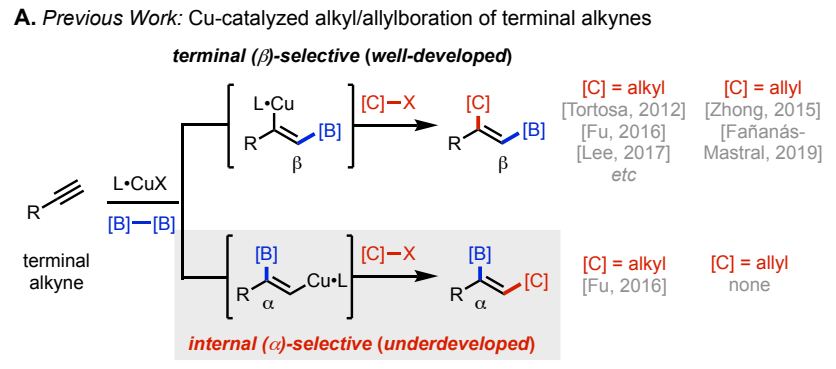

B. Cu-catalyzed $\beta$-selective alkylboration of terminal alkynes [Fu, 2016]

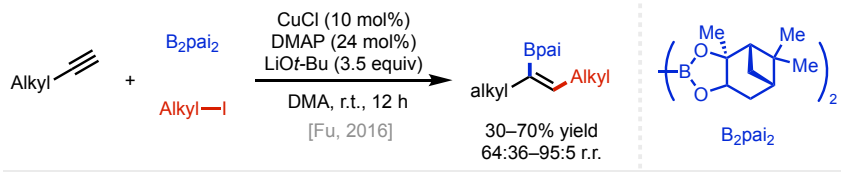

C. This Work: (CAAC)Cu-catalyzed $\alpha$-selective alkyl/allylboration of terminal alkynes

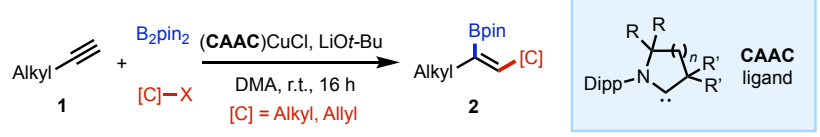

Scheme 1. Overview of Cu-catalyzed regioselective carboboration of terminal alkynes.

Regioselectivity trends in $\mathrm{L}_{n} \cdot \mathrm{Cu}$-boryl alkyne addition processes are complex and reflect an interplay between the steric and electronic properties of the ligand, the identity of the boryl group, and the substituent(s) on the alkyne substrate. ${ }^{[14-16]} \mathrm{N}$ Heterocyclic carbene $(\mathrm{NHC})$ ligands ${ }^{[17-18]}$ have been widely used in catalytic $\mathrm{L}_{n} \cdot \mathrm{Cu}$-boryl catalysis and generally favor boryl transfer to the terminal position of terminal alkynes with Bpin and related boryl groups, though either position can predominate depending on the nature of substrate and the ligand environment around 
boron. We recently demonstrated that strongly $\sigma$-donating CAAC ligands ${ }^{[19-21]}$ override substituent effects of the boryl group and the alkyne, allowing for reliably Markovnikov ( $\alpha$-selective) protoboration of diverse terminal alkynes with a variety of bisboron nucleophiles. ${ }^{[22]}$ Based on this result, we questioned whether it would be possible to employ $\mathrm{C}\left(\mathrm{sp}^{3}\right)$-based electrophiles in lieu of a proton to develop a three-component carboboration, with regioselectivity and product substitution patterns that would complement existing methodology. ${ }^{[23-32]}$ Of relevance to this proposal, Xiao and Fu disclosed an important study in which the combination of $\mathrm{CuCl}(10 \mathrm{~mol} \%)$ as precatalyst, DMAP (24 mol\%) as ligand, and $\mathrm{B}_{2}$ pai ${ }_{2}$ (pai $=(+)$-pinanediolato) as bis-boron reagent leads to branched-selective carboboration, though in this case yields and regioselectivity were variable $(30-70 \%$ yield, 64:36-95:5 r.r.). The less common and more expensive $B_{2}$ pai 2 nucleophile was employed to maximize regioselectivity, and some synthetically useful carbogenic groups were incompatible with this protocol (e.g., allyl electrophiles). ${ }^{[3]}$

To reduce this idea to practice, we examined carboboration of model terminal alkyne 1a with two representative carbon electrophiles, allyl diethyl phosphate and methyl iodide. The former was selected because allyl electrophiles have not been previously employed in $\alpha$-selective carboboration of alkynes, despite being used in several reports of linear selectivity. ${ }^{[30-32,34]}$ The latter was selected because it was found to be low-yielding under previously published conditions (one example, 87:13 r.r., $32 \%$ yield). ${ }^{[33]}$

Table 1. Optimization of reaction conditions. ${ }^{[a]}$
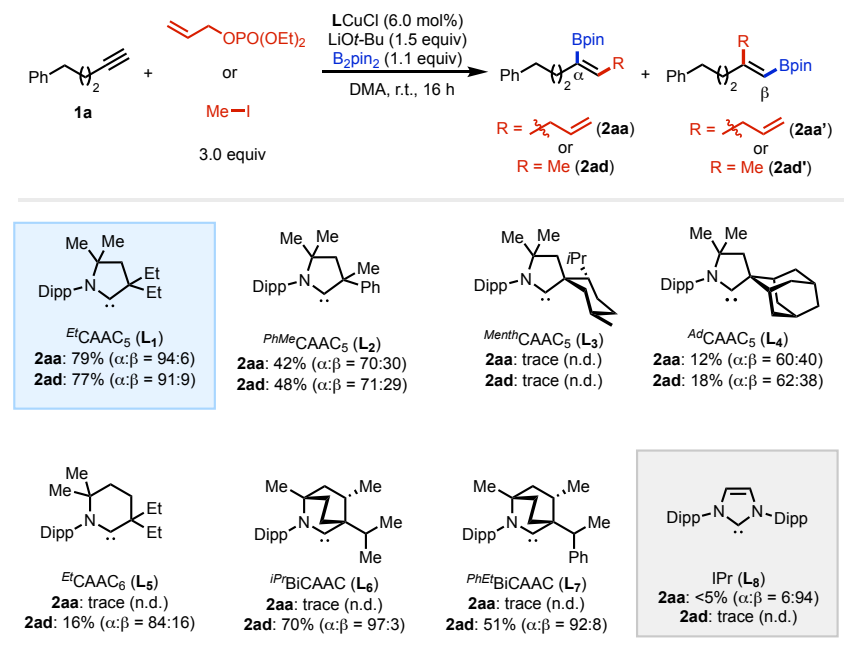

[a] Yields of products (2aa or 3aa) and regioselectivity ( $\pm 2 \%$ ) were determined by ${ }^{1} \mathrm{H}$ NMR spectroscopy $(600 \mathrm{MHz})$ using $\mathrm{CH}_{2} \mathrm{Br}_{2}$ as the internal standard. n.d. $=$ not determined.

A library of $\mathrm{CAAC} \cdot \mathrm{CuCl}$ precatalysts with different steric and electronic properties was tested, and a summary of the data is shown in Table 1. To our delight, ${ }^{E t} \mathrm{CAAC}_{5}$-ligated $\mathrm{Cu}$ complex $\left(\mathrm{L}_{1} \mathrm{CuCl}\right)$ promoted both transformations with high conversion and high $\alpha$-selectivity. Replacement of the ethyl groups on the $\alpha$ carbon of $\mathbf{L}_{1}{ }^{[35]}$ with either an electron-withdrawing group $\left(\mathbf{L}_{2}\right)^{[36]}$ or more sterically bulky groups $\left(\mathbf{L}_{3}, \mathbf{L}_{4}\right)^{[35,37]}$ led to decreased yield and $\alpha: \beta$ ratio. ${ }^{E t} \mathrm{CAAC}_{6}$ ligand $\left(\mathrm{L}_{5}\right),{ }^{[38]}$ a much stronger electrondonor than $\mathbf{L}_{1}$, gave poor yields in both transformations, though high $\alpha$ : $\beta$ ratio $(84: 16)$ was observed in the methylboration reaction.
Interestingly, BiCAAC ligands, ${ }^{[39]}$ i-PrBiCAAC $\left(\mathbf{L}_{6}\right)$ and ${ }^{\text {PhEt}}{ }^{\mathrm{BiCAAC}}$ $\left(\mathbf{L}_{7}\right)$, which are also strong electron-donors, furnished the desired product methylborylated product 2 ad with high a-selectivity (97\% and $92 \%$, respectively). But neither of them could deliver any desired allylborylated product 2aa. Moreover, further exploration of substrate scope for methylboration using $\mathbf{L}_{6}$ suggested that this ligand could not tolerate the presence of Lewis basic functional groups. For example, when an ether-containing substrate was attempted (see $\mathbf{2 k d}$ below), only $23 \%$ yield and $47 \%$ a-selectivity were observed. A control experiment with IPr, a representative $\mathrm{N}$ heterocyclic carbene ligand commonly used in copper-boryl chemistry, ${ }^{[10-13]}$ led to low yield with both electrophiles

Table 2. Scope of $\alpha$-selective allylboration of terminal alkynes. ${ }^{[a]}$

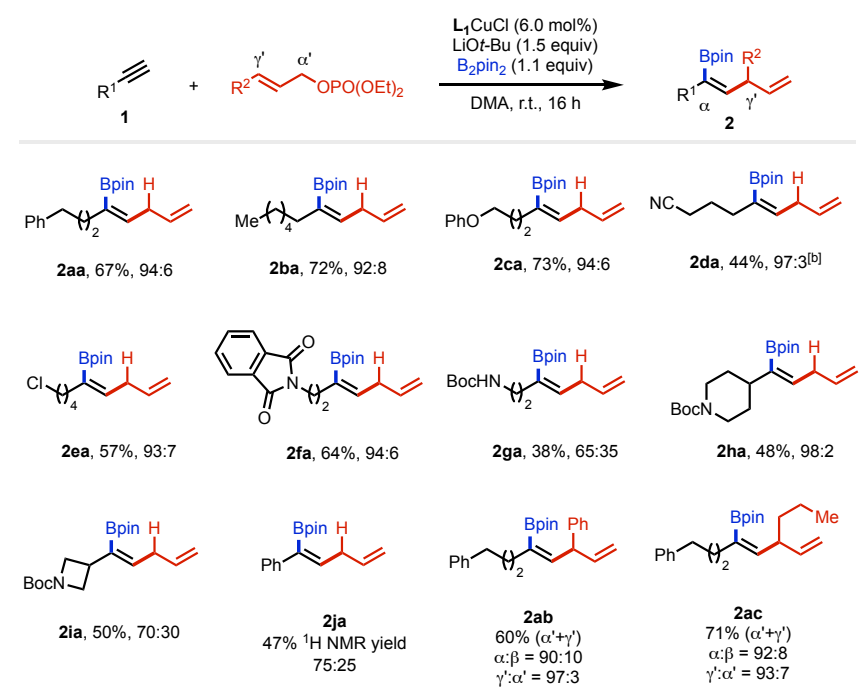

[a] Conditions: 1 (0.10 mmol), $B_{2} \operatorname{pin}_{2}(0.11 \mathrm{mmol})$, allyl electrophile $(0.30 \mathrm{mmol})$, $\mathrm{L}_{1} \mathrm{CuCl}(0.006 \mathrm{mmol}), \mathrm{LiOt}-\mathrm{Bu}(0.15 \mathrm{mmol})$ and DMA $(0.60 \mathrm{~mL})$, r.t. Ratios of $\alpha: \beta( \pm 2)$ were determined via ${ }^{1} \mathrm{H}$ NMR spectroscopy $(600 \mathrm{MHz})$ of the crude reaction mixtures. Percentages represent isolated yields of the $\alpha$-borylated.

With the optimized conditions in hand, we examined the scope of the allylboration reaction. Terminal alkynes bearing primary alkyl groups provided the corresponding products in excellent yields with high levels of regioselectivity (2aa and $\mathbf{2 b a}$ ). In addition, functional groups such as ether (2ca), cyano (2da), halogen (2ea), protected amines (2fa and $2 \mathbf{g a}$ ) and pendant piperidine (2ha) and azetidine (2ia) were well tolerated, furnishing desired products in good yields and high a-selecitivity, except in the case of $\mathbf{2 g a}$ and $\mathbf{2 i a}$, where moderate $\alpha$-selectivity $(65 \%$ and $70 \%$, respectively) was observed. Notably, when phenylacetylene was subjected to the optimal reaction conditions, the desired product 2 ja was generated with $75 \%$ a-selectivity. Allyl electrophiles with phenyl and $n$-propyl groups substituted at $\gamma$ position were also compatible under the reaction conditions, furnishing desired products in high yields $(60-71 \%)$ and excellent regioselectivity (>90\% a-borylation, 93-97\% $\mathrm{S}_{N} 2$ ' allylation) (2ab and 2ac).

We next explored the scope of terminal alkynes for alkylboration. Alkynes containing different primary alkyl chains readily underwent efficient methylboration with high $\alpha$-selectivity ( $\mathbf{2 a d}$ and $\mathbf{2 b d}$ ). In addition, a range of functional groups, including ether (2kd), chloro (2ed, $\mathbf{2 m d}$ ), cyano (2cd), amide (2od) and protected amino group (2/d), were tolerated, furnishing the desired products in good yields and high regioselectivity. The 
reactions of alkynes bearing secondary alkyl groups at the $\alpha$ position (2qd and $\mathbf{2 r d}$ ) gave high $\alpha$-selectivity as well. However, similarly to the previous reported (CAAC)Cu-catalyzed protoboration reactions, tert-butyl acetylene (2td) has very low reactivity under the optimal conditions. Alkynes with medicinally relevant functional groups like pendant piperidine and azetidine were both competent reactants ( $\mathbf{2} \mathbf{h d}$ and $\mathbf{2 i d}$ ). Unfortunately, poor $\alpha$-selectivity was observed when benzyl protected propargyl alcohol (2sd) or phenylacetylene (2jd) was used as substrate.

Table 3. Scope of $\alpha$-selective alkylboration of terminal alkynes. ${ }^{[a]}$

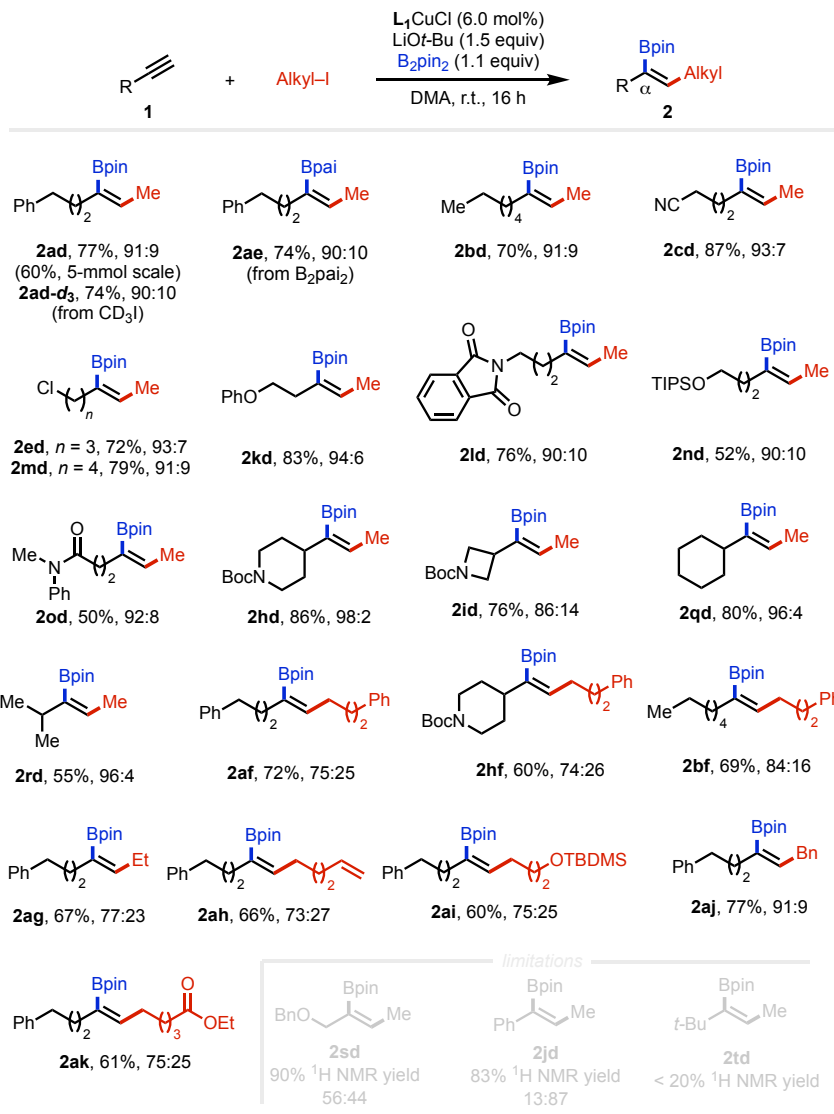

[a] Conditions: $1(0.10 \mathrm{mmol}), \mathrm{B}_{2}$ pin $2(0.11 \mathrm{mmol})$, alkyl iodide $(0.30 \mathrm{mmol})$, $\mathrm{L}_{1} \mathrm{CuCl}(0.006 \mathrm{mmol})$, LiOt-Bu $(0.15 \mathrm{mmol})$ and DMA $(0.60 \mathrm{~mL})$, r.t. Ratios of $\alpha: \beta( \pm 2)$ were determined via ${ }^{1} \mathrm{H}$ NMR spectroscopy $(600 \mathrm{MHz})$ of the crude reaction mixtures. Percentages represent isolated yields of the $\alpha$-borylated products. [b] The corresponding protoboration side product (23\%) was observed by ${ }^{1} \mathrm{H}$ NMR analysis of the crude reaction mixture.

We then moved on to explore the scope of the alkyl electrophile. Deuterated methyl iodide works well, showing the ability of this method to assemble specifically labelled compounds efficiently. The reactions of primary alkyl electrophiles with $\mathbf{1 a}$ afforded the $\alpha$-selective alkylboration products with high yield, though relatively lower $\alpha: \beta$ ratios were observed compared to the reaction using methyl iodide (2af, 2ag). Notably, the alkyl electrophiles with functional groups, such as terminal alkene, silyl ether and ester, were compatible under our reaction conditions, giving $60 \%-66 \%$ yield and $73 \%-75 \%$ a-selectivity (2ah-2aj). When benzyl bromide was used as electrophile, the desired product (2ak) was generated in excellent yield and high $\alpha$ selectivity. Similar $\alpha$ : $\beta$ ratio was observed when an alkyne bearing secondary alkyl groups at the $\alpha$-position was applied (2hf).

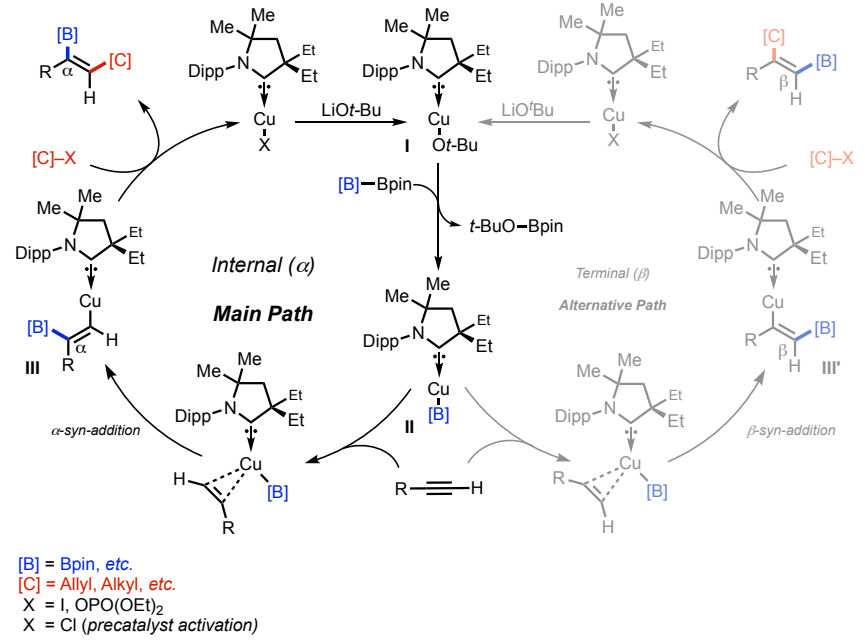

Scheme 2. Proposed mechanism.

A plausible catalytic cycle for this reaction is depicted in Scheme 2. One possible explanation for the observation that regioselectivity varies across the different $\mathrm{C}\left(\mathrm{sp}^{3}\right)$ electrophiles tested in Table 3 is that the borylcupration step could be reversible. Under such a scenario, the nature of the $\mathrm{C}\left(\mathrm{sp}^{3}\right)$ electrophile and the rate of $\mathrm{C}-\mathrm{C}$ bond formation may influence regioselectivity.

In conclusion, we have extended our investigations of (CAAC)Cu-boryl catalysis to the three-component carboboration of terminal alkynes and have found that high levels of a-selectivity are maintained across different carbon electrophiles, including allyl electrophiles, which have not been previously employed in an $\alpha$-selective reaction system. The generality of the method across different alkyne substrates offers a convenient means of preparing tri-substituted alkenylboron compounds with established utility in organic synthesis.

\section{Acknowledgements}

This work was financially supported by the National Institutes of Health (5R35GM125052-04 and diversity supplement, 5R35GM125052-04S1) and an ACS PRF Doctoral New Investigator Grant (K.M.E.). This work was also supported by the U.S. Department of Energy, Office of Science, Basic Energy Sciences, Catalysis Science Program, under Award No. DESC0009376 (G.B.), National Science Foundation Award No. CHE-1800598 (D.B.G.), and the Agence Nationale de la Recherche Award No. ANR-19-276CE07-0017 (R.J). Thanks are due to San Diego State University for initial support of this work by a SDSU University Graduate Fellowship (S.Y.)

Keywords: organoboron - copper - carboboration - CAAC ligand $\cdot$ regioselectivity

[1] N. Miyaura, A. Suzuki, Chem. Rev. 1995, 95, 2457-2483. 
[2] H. K. Scott, V. K. Aggarwal, Chem. Eur. J. 2011, 17, 13124-13132

[3] A. J. J. Lennox, G. C. Lloyd-Jones, Chem. Soc. Rev. 2014, 43, 412-443.

[4] M. J. West, J. W. B. Fyfe, J. C. Vantourout, A. J. B. Watson, Chem. Rev. 2019, 119, 12491-12523.

[5] J. P. M. António, R. Russo, C. P. Carvalho, P. M. S. D. Cal, P. M. P. Gois Chem. Soc. Rev. 2019, 48, 3513-3536.

[6] S. J. Baker, C. Z. Ding, T. Akama, Y.-K. Zhang, V. Hernandez, Y. Xia Future Medicinal Chemistry 2009, 1, 1275-1288.

[7] F. Jäkle, Coord. Chem. Rev. 2006, 250, 1107-1121.

[8] S. K. Mellerup, S. Wang, Chem. Soc. Rev. 2019, 48, 3537-3549.

[9] J. Miao, Y. Wang, J. Liu, L. Wang, Chem. Soc. Rev. 2022, 51, 153-187.

[10] H. Yoshida, ACS Catal. 2016, 6, 1799-1811.

[11] D. Hemming, R. Fritzemeier, S. A. Westcott, W. L. Santos, P. G. Steel, Chem. Soc. Rev. 2018, 47, 7477-7494.

[12] J. Carreras, A. Caballero, P. J. Pérez, Chem. Asian J. 2019, 14, 329 343

[13] A. Whyte, A. Torelli, B. Mirabi, A. Zhang, M. Lautens, ACS Catal. 2020, 10, 11578-11622.

[14] T. Tsushima, H. Tanaka, K. Nakanishi, M. Nakamoto, H. Yoshida, ACS Catal. 2021, 11, 14381-14387.

[15] H. Jang, A. R. Zhugralin, Y. Lee, A. H. Hoveyda, J. Am. Chem. Soc. 2011 133, 7859-7871.

[16] A. L. Moure, P. Mauleón, R. Gómez Arrayás, J. C. Carretero, Org. Lett 2013, 15, 2054-2057.

[17] M. N. Hopkinson, C. Richter, M. Schedler, F. Glorius, Nature 2014, 510 485-496.

[18] S. Díez-González, N. Marion, S. P. Nolan, Chem. Rev. 2009, 109, 3612 3676.

[19] R. Jazzar, M. Soleilhavoup, G. Bertrand, Chem. Rev. 2020, 120, 41414168.

[20] J. Morvan, M. Mauduit, G. Bertrand, R. Jazzar, ACS Catal. 2021, 11, 1714-1748.

[21] M. Melaimi, R. Jazzar, M. Soleilhavoup, G. Bertrand, Angew. Chem. 2017, 129, 10180-10203; Angew. Chem. Int. Ed. 2017, 56, 1004610068.

[22] Y. Gao, S. Yazdani, A. Kendrick IV, G. P. Junor, T. Kang, D. B. Grotjahn, G. Bertrand, R. Jazzar, K. M. Engle, Angew. Chem. 2021, 133, 20024 20031; Angew. Chem. Int. Ed. 2021, 60, 19871-19878.

[23] R. Alfaro, A. Parra, J. Alemán, J. L. García Ruano, M. Tortosa, J. Am Chem. Soc. 2012, 134, 15165-15168.

[24] L. Zhang, J. Cheng, B. Carry, Z. Hou, J. Am. Chem. Soc. 2012, 134, 14314-14317.

[25] H. Yoshida, I. Kageyuki, K. Takaki, Org. Lett. 2013, 15, 952-955.

[26] T. Itoh, Y. Shimizu, M. Kanai, J. Am. Chem. Soc. 2016, 138, 7528-7531.

[27] Y. Zhou, W. You, K. B. Smith, M. K. Brown, Angew. Chem. 2014, 126 3543-3547; Angew. Chem. Int. Ed. 2014, 53, 3475-3479.

[28] L.-J. Cheng, N. P. Mankad, Angew. Chem. 2018, 130, 10485-10489; Angew. Chem. Int. Ed. 2018, 57, 10328-10332.

[29] O. Zhurakovskyi, R. M. P. Dias, A. Noble, V. K. Aggarwal, Org. Lett. 2018 20, 3136-3139.

[30] H.-Y. Bin, X. Wei, J. Zi, Y.-J. Zuo, T.-C. Wang, C.-M. Zhong, ACS Catal. 2015, 5, 6670-6679

[31] J. Mateos, E. Rivera-Chao, M. Fañanás-Mastral, ACS Catal. 2017, 7 , 5340-5344.

[32] E. Rivera-Chao, M. Mitxelena, J. A. Varela, M. Fañanás-Mastral, , Angew Chem. 2019, 131, 18398-18402; Angew. Chem. Int. Ed. 2019, 58 18230-18234.

[33] W. Su, T.-J. Gong, Q. Zhang, Q. Zhang, B. Xiao, Y. Fu, ACS Catal. 2016 6, 6417-6421.

[34] Control experiments revealed that the a-selective reaction conditions from Ref. 33 did not lead to appreciable product formation $(<5 \%)$ when allyl electrophiles were employed.

[35] V. Lavallo, Y. Canac, C. Prasang, B. Donnadieu, G. Bertrand, Angew. Chem. 2005, 117, 5851-5855; Angew. Chem. Int. Ed. 2005, 44, 57055709 .

[36] J. Morvan, F. Vermersch, Z. Zhang, L. Falivene, T. Vives, V. Dorcet, T. Roisnel, C. Crévisy, L. Cavallo, N. Vanthuyne, G. Bertrand, R. Jazzar, M. Mauduit, J. Am. Chem. Soc. 2020, 142, 19895-19901.
[37] V. Lavallo, G. D. Frey, S. Kousar, B. Donnadieu, G. Bertrand, Proc. Natl. Acad. Sci. USA 2007, 104, 13569-13573.

[38] C. M. Weinstein, G. P. Junor, D. R. Tolentino, R. Jazzar, M. Melaimi, G. Bertrand. J. Am. Chem. Soc. 2018, 140, 9255-9260.

[39] E. Tomás-Mendivil, M. M. Hansmann, C. M. Weinstein, R. Jazzar, M. Melaimi, G. Bertrand, J. Am. Chem. Soc. 2017, 139, 7753-7756. 


\section{Entry for the Table of Contents}
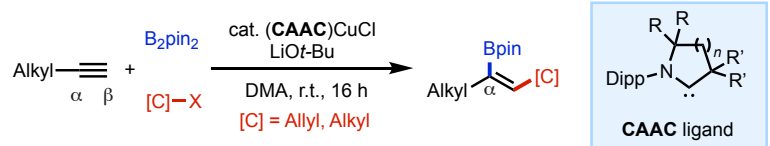

three-component alkyne carboboration

- broad alkyne scope

- mild reaction conditions
highly $\alpha$-selective (up to >98:2)

Copper-catalyzed, three-component, $\alpha$-selective allyl- and alkylboration of terminal alkynes is achieved by utilizing strongly $\sigma$-donating cyclic(alkyl)(amino)carbene CAAC ligands. The method exhibits broad alkyne scope and tolerates various carbon electrophiles, providing an expedient approach to versatile trisubstituted alkenylboron building blocks.

Institute and/or researcher Twitter usernames: @gytyw @Nana_Kem22 @YazdaniSimaChem @DouglasGrotjahn

@Rodolphe_Jazzar @englelab @SDSU @UCSDChemBiochem @ScrippsResearch 